\title{
EDITORIAL
}

Como é de conhecimento dos leitores, Interação em Psicologia conta, desde 2006, com uma versão eletrônica (www.ser.ufpr.br/psicologia), além de sua versão impressa. Quanto a isso, duas características merecem especial destaque. A primeira diz respeito ao acesso gratuito e irrestrito a todo conteúdo da revista - que caracteriza não apenas nosso periódico, mas todos aqueles presentes no Sistema Eletrônico de Revistas (SER) da Universidade Federal do Paraná. Corroborando uma tendência geral no campo da divulgação da informação científica, as entidades que representam a produção científica da psicologia brasileira têm apoiado de forma enfática as políticas de acesso aberto - com destaque para a Associação Nacional de Pesquisa e Pós-graduação em Psicologia (ANPEPP). A revista Interação em Psicologia tem feito sua parte, e apóia todas as iniciativas que contribuam para a democratização do acesso à produção científica.

Para além do acesso aberto, no entanto, o SER permitiu também a realização de todo o processo editorial por via eletrônica, o que dinamizou sobremaneira a comunicação entre as partes envolvidas. O fluxo de artigos recebidos por nossa revista tem aumentado significativamente. Diversos fatores ajudam a explicar este aumento, mas a facilidade para envio e acompanhamento de artigos certamente tem papel importante.

Vários periódicos brasileiros no campo da psicologia têm adotado a editoração eletrônica - certamente, uma tendência natural. Conforme a editoração eletrônica torne-se familiar a todos - editores, consultores e autores - seu manejo igualmente o fará. Sugestões para o aprimoramento do sistema de editoração são sempre bem-vindas, e recebemos tais sugestões com freqüência. Algumas delas são imediatamente adotadas. Contudo, considerando que há limites para as modificações que podem ser implantadas diretamente pelos editores, não é possível acolher todas as sugestões. Ainda assim, todas elas são igualmente consideradas pela Comissão Editorial, sendo encaminhadas, quando pertinente, para as instâncias responsáveis.

A disposição em realizar tais sugestões demonstra o zelo de autores e consultores para com a qualidade da divulgação científica no campo da psicologia. Agradecemos a todos que têm contribuído, desta e de outras maneiras, para o aprimoramento de nossa publicação.

\section{Alexandre Dittrich}

Editor 